\title{
Measuring inorganics in biomass fast pyrolysis oils
}

Charles-Philippe LIENEMANN, Alain QUIGNARD, Nathalie TEXIER, Nadège CHARON

IFP Energies nouvelles, Rond-point de l'échangeur de Solaize, BP3, 69360 Solaize, France

\section{Appendix 1: analytical protocols}

\section{Wondimu protocol}

Weigh precisely $0.1 \mathrm{~g}$ of samples in a Teflon reactor, add $8 \mathrm{~mL}$ of $\mathrm{HNO}_{3}$ and $2 \mathrm{~mL}$ of $\mathrm{H}_{2} \mathrm{O}_{2}$. Apply the following program and when the mineralization is completed, flush the Teflon reactor with ultrapure water and adjust to $25 \mathrm{~mL}$ :

Table 1. Experimental conditions (i.e. power, residence time and temperature) for the Wondimu protocol

\begin{tabular}{|c|c|c|}
\hline Power (W) & Time & Temperature $\left({ }^{\circ} \mathrm{C}\right)$ \\
\hline 800 & $2 \min ($ ramp) & 100 \\
\hline 800 & $30 \mathrm{sec}$ (ramp) & 75 \\
\hline 800 & $10 \min ($ ramp) & 200 \\
\hline 800 & $30 \mathrm{sec}$ (hold) & 200 \\
\hline 800 & $10 \min ($ ramp) & 220 \\
\hline 800 & $30 \mathrm{sec}$ (hold) & 220 \\
\hline 800 & 9 min 30 sec (ramp) & 200 \\
\hline 800 & $30 \mathrm{sec}$ (hold) & 200 \\
\hline 800 & $3 \min ($ ramp) & 230 \\
\hline
\end{tabular}

\section{Ashes mineralization protocol}

Weigh precisely $0.1 \mathrm{~g}$ of samples in a Teflon reactor, add $8 \mathrm{~mL}$ of $\mathrm{HNO}_{3}$. Apply the following program: 
Table 2. Experimental conditions (i.e. power, residence time and temperature) for the ashes mineralization protocol (first step)

\begin{tabular}{|c|c|c|}
\hline Power $(\mathbf{W})$ & Time & Temperature $\left({ }^{\circ} \mathbf{C}\right)$ \\
\hline 800 & 5 min (ramp) & 180 \\
800 & 10 min (hold) & 180 \\
\hline
\end{tabular}

Open carefully the Teflon reactor and add $2 \mathrm{ml}$ of HF, apply the second program:

Table 3. Experimental conditions (i.e. power, residence time and temperature) for the ashes mineralization protocol (second step)

\begin{tabular}{|c|c|c|}
\hline Power $(\mathbf{W})$ & Time & Temperature $\left({ }^{\circ} \mathbf{C}\right)$ \\
\hline 800 & $5 \min ($ ramp) & 220 \\
800 & $10 \min ($ hold $)$ & 220 \\
\hline
\end{tabular}

If possible, evaporate the $\mathrm{HF}$ and dilute the residue with $1 \mathrm{ml}$ of $\mathrm{HNO}_{3}$. Flush the Teflon tubes with ultrapure water and adjust to $25 \mathrm{~mL}$.

\section{ISO 16967 Method}

Weigh precisely $0.1 \mathrm{~g}$ of samples in a Teflon tubes, add $1.6 \mathrm{~mL}$ of $\mathrm{HNO}_{3}, 0.2 \mathrm{~mL}$ of $\mathrm{HF}$ and $0.6 \mathrm{~mL}$ of $\mathrm{H}_{2} \mathrm{O}_{2}$. Apply the following program:

Table 4. Experimental conditions (i.e. power, residence time and temperature) for the ISO 16967 method protocol (first step)

\begin{tabular}{|c|c|c|}
\hline Power $(\mathbf{W})$ & Time & Temperature $\left({ }^{\circ} \mathbf{C}\right)$ \\
\hline 1500 & 15 min (ramp) & 190 \\
1500 & 10 min (hold) & 190 \\
\hline
\end{tabular}

Neutralize with $2 \mathrm{~mL}$ of $\mathrm{H}_{3} \mathrm{BO}_{3}$ and apply the following program:

Table 5. Experimental conditions (i.e. power, residence time and temperature) for the ISO 16967 method protocol (second step)

\begin{tabular}{|c|c|c|}
\hline Power(W) & Time & Temperature $\left({ }^{\circ} \mathbf{C}\right)$ \\
\hline 1500 & $2 \min ($ ramp) & 150 \\
1500 & $15 \min ($ hold $)$ & 150 \\
\hline
\end{tabular}

When the neutralization is completed, flush the Teflon tubes with ultrapure water and adjust to $25 \mathrm{~mL}$. 
Appendix 2: validation of the ISO 16967 a method applied for (a) the bush branches and leaves reference material and (b) the wood fuel material reference material. Expected and measured contents are represented respectively in grey and white bars. Confidence interval is given.

Figure 1. Expected elements contents and measured elements contents using the ISO 16967 method for (a) the bush branches and leaves reference material and (b) the wood fuel material reference material.

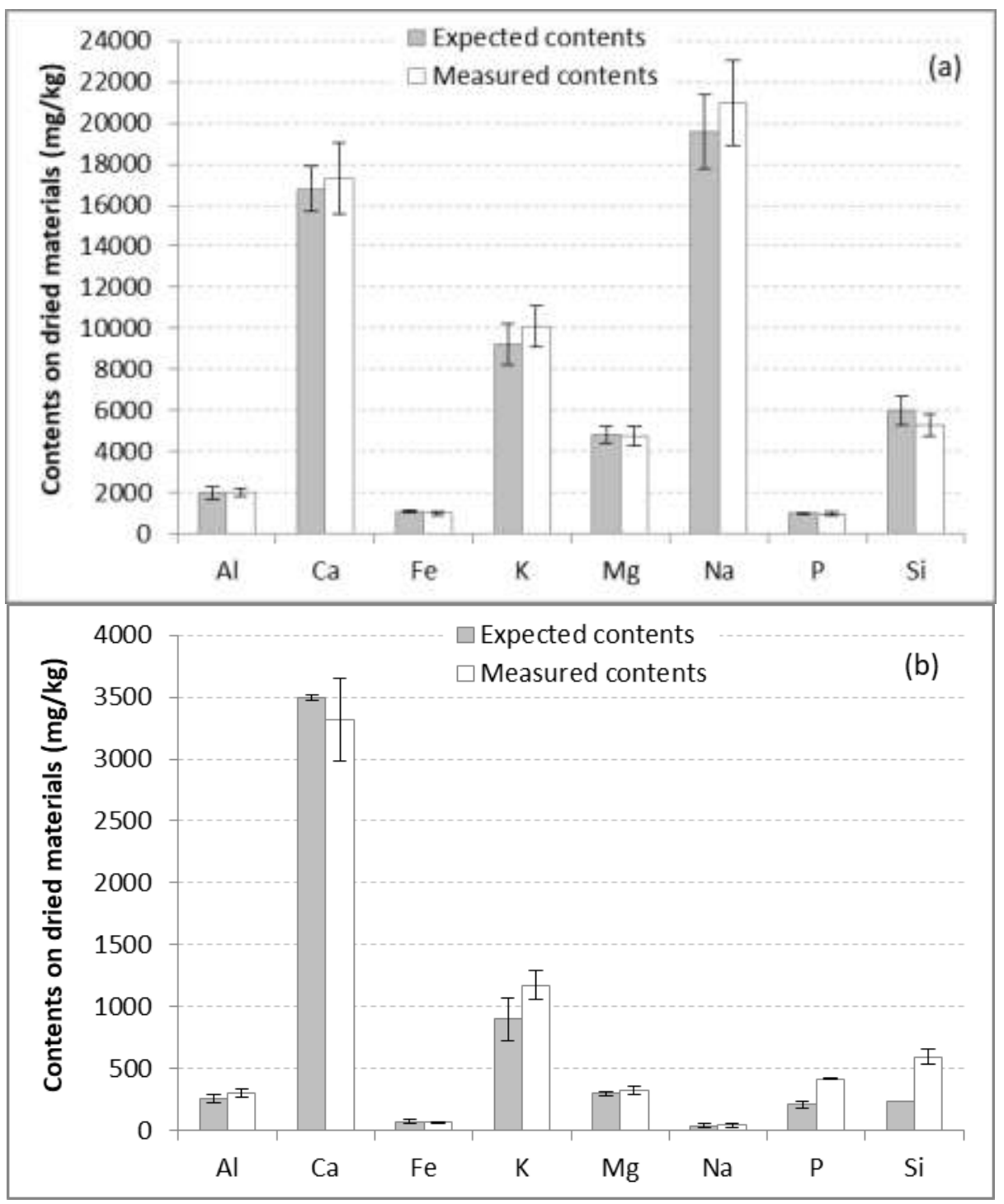

